\title{
Preparing a medico-legal report
}

\section{Robert Bluglass}

The preparation of medico-legal reports is an increasingly important responsibility for the psychiatrist as legislation and administrative regulations become more complex and litigation increases.

The report may be prepared by a patient's consultant (or responsible medical officer) who has a specialised knowledge of the patient's history, illness, care and treatment, or by a psychiatrist acting as an independent expert who is providing an evaluation to assist a court or other tribunal.

Examples of the first category include reports required routinely under the provisions of the Mental Health Act 1983 (Box 1), reports to the coroner following sudden death, and reports to a tribunal of inquiry following a serious incident involving a patient or a hospital.

The second category includes cases such as the assessment of a person of whom the psychiatrist has no previous knowledge, and who is charged with an alleged offence and suspected of suffering from a form of mental disorder. Other examples include the request for an independent assessment by an applicant to a mental health review tribunal, the provision of an opinion for a hospital Trust or patient with reference to an allegation of medical

Box 1. Examples of reports required under the Mental Health Act 1983

Managers' application

Mental health review tribunals

Reports to Home Secretary on restricted patients

Recommendation to transfer convicted or remanded prisoners to hospital

Court protection

Supervised discharge review (subject to legislation) or nursing negligence, the assessment of a plaintiff claiming compensatory damages resulting from an accident or injury (on behalf of either the plaintiff or the defendant), or the provision of evidence of good psychiatric practice in less common actions such as libel suits involving medical practitioners.

Psychiatrists are often required to assist in criminal or civil proceedings and take the role of either a professional or an expert witness, depending upon the function they have been requested to perform.

If the psychiatrist is providing a report relating to facts of which he has prior knowledge, he is usually acting as a professional witness. The expert provides evidence which is outside the experience of a court, judge or jury. When acting as a professional witness, the psychiatrist may also be invited to give an opinion upon the inference to be drawn from the facts which he reports, and so take on the role of expert. Experts acting in an independent capacity will usually not know the subject or circumstances previously.

The general rule relating to evidence is that witnesses give evidence on facts, while the inference to be drawn from these facts is a matter for the judge or jury. If the witness offers an opinion, the function of the jury is usurped. There are, however, exceptions to this rule. The opinion of experts is admissible where competency to form and opinion upon a subject can only be acquired by a course of special study, and where the judge or jury could not otherwise form an opinion. The scope and limitations of expert opinion is established by the law of evidence of each jurisdiction (there are differences between the jurisdictions of the United Kingdom; see for example May (1995)). It is helpful to have some basic understanding of these rules which indicate what evidence is admissible, and what should be avoided and may lead to objection in court. Although 'hearsay' is usually inadmissible by witnesses as to fact (e.g. what a witness reports

Robert Bluglass, FRCPych, MRCP, DPM, is Professor of Forensic Psychiatry at the University of Birmingham and a consultant in forensic psychiatry; he is Clinical Director of the Reaside Clinic, Birmingham, and of the West Midlands Forensic Psychiatry Service. He has 30 years' experience of preparing reports. 
Box 2. Matters requiring expert opinion in the criminal court

Fitness to appear in court

Fitness to plead and stand trial

Criminal responsibility of defendant

Insanity

Diminished responsibility

Infanticide

Automatism

Effects of drugs or medication

Disposal of convicted defendant

Fitness of a witness to give reliable evidence

someone else told him), more flexibility is accepted in a psychiatric report if it can be justified to support the assessment. Clearly the account given to the doctor by a patient is crucial in determining a diagnosis.

Psychiatrists assisting criminal courts most commonly provide a medico-legal report about disposal following conviction and may, for example, ask for a hospital order or probation order with a requirement of treatment as an alternative to any other disposal the court may have in mind. There are, however, a range of other issues which also often require an opinion (see Box 2). The list provided is not exhaustive. For civil proceedings some of the issues which often require expert opinion are summarised in Box 3 . The rules of evidence differ between criminal and other courts or tribunals.

\section{General principles}

The opinion provided in a medico-legal report is dependent upon the accuracy and validity of the facts upon which it is based. The facts will usually result from the examination of a patient, reading of papers and interviews with relatives or others.

\section{Interviewing the patient}

It is important to allow sufficient time for the interview of the patient and to extend it to more than one session if necessary. When the examination is for an expert opinion, this should be made clear to the patient. He should understand that the interview is for a medico-legal report, not a diagnostic opinion or for the prospect of treatment. The normal expectation of confidentiality between doctor and patient does not exist, or is limited, and the report may be seen by others including a solicitor, judge, counsel or others. The patient should understand the purpose of the interview, who has requested it, and to whom the doctor will report.

The examiner is not an advocate representing a client's interests but an independent medical expert who will be as dispassionate as he can. It is the lawyers whose principal duty is to represent their client's best interests as they see it. The psychiatrist reporting to one side or the other may find it difficult to maintain his objectivity once he is drawn into the complexities of adversarial legal conflict, but he should always endeavour to do so. Ways of rationalising the use of experts in the judicial system and ensuring their independence are currently under discussion.

Where appropriate, the psychiatric interview should be followed by a physical examination and any necessary tests. These procedures may require further time to be spent on the preparation of the report.

\section{Interviewing third-party members}

It is also valuable as a routine to request an interview with a spouse or close relative who may be able to give an independent view of the patient's background and usual behaviour or performance.

Depending upon the nature of the report, the examiner will be provided with papers to study and digest. These may be voluminous, including reports from other specialists or hospital records, school reports, statements or depositions (witness statements). It is important to request whatever might be relevant if not provided. In criminal cases there are sometimes audio tapes, and in compensation claims video surveillance cassettes may be available. Although sometimes difficult, the

Box 3. Issues requiring expert opinion in the civil court

Compensation claims following injury or neglect

Medical negligence and failure of duty of care

Professional competence (doctor or other professional)

Reports for children and youth courts

Other litigation 
examiner should negotiate sufficient time to examine all this material carefully. It is unwise to depend upon the analyses of documentation undertaken by other experts involved in the case. Medical records often reveal important historical material, descriptions of behaviour or of treatment which may substantially differ from the account given by the subject and shed a different light on the case.

\section{Structure of the report}

The format of the report will vary depending whether it is for a tribunal, statutory body or a court. If it is for legal proceedings, the content will vary between criminal and civil actions, but general principles apply:

Jargon-free. It is important to bear in mind that a medico-legal report is usually an opinion addressed to laymen who are not themselves experts. Although lawyers and judges who frequently deal with medical matters gain a knowledge of psychiatric terminology, it can often be inaccurate and no assumptions should be made. The report should be written in clear and understandable English, with as little use of technical terms and professional jargon as possible. When a technical term is used it must always be explained (in parentheses if necessary) in a manner that can be easily understood. The writer should edit the report to ensure that any terms that have slipped in inadvertently, such as 'psychotic' or 'delusion', are qualified.

Facts versus opinion. Whatever the purpose of the report, the author should remember that opinion should be clearly differentiated from the facts upon which the report is based. The facts include the undisputed background information, the history and the examination findings. The opinion is the expert evaluation of the significance of these facts, together with a conclusion which should include specific recommendations relevant to the issue in hand and, if appropriate, an assessment of risk or dangerousness and prognosis for the future. It is important to remember that negative findings are of as much value to the judicial process as positive ones.

Keep to your subject. The psychiatrist should not stray beyond his expertise to provide an opinion upon matters about which he is unable to demonstrate special qualification or experience, such as orthopaedics or cardiology.
Independence. The author should try to be as independent and unbiased as possible. A report requested on behalf of a plaintiff or a defendant does not imply that the psychiatrist has a responsibility to help to obtain damages or gain an acquittal. These are matters that concern the lawyers. If the conclusion does not assist the client, then the report may or may not be used. It may well, however, have assisted those who requested it in understanding the reality of the case.

Length of the report. The report should be comprehensive without being unnecessarily wordy and over-inclusive. Its length should be dictated by the complexity of the matter under consideration. This is a delicate balance to get right; reports of exceptional brevity are usually of little value. It is important to be clear at the outset what the issues in a particular case are and, if the report has been requested from an outside agent, to read the requesting letter from time to time to ensure that the issues are well in mind when writing the report and to check that they have been clearly addressed.

\section{Layout of the report}

No particular format is essential, but the following guidance may be helpful and is often adopted by those regularly preparing medico-legal reports (see also Box 4).

1. The report should be typed on A4 paper, using double or $1 \frac{1}{2}$-line spacing, with one inch margins.

2. The first page should show:

a) The name of the subject (and sometimes date of birth).

b) A short summary indicating the purpose of the report, e.g. 'This report is prepared at your request to provide a psychiatric opinion upon Mr A.B. who was involved in a road traffic accident on 1st October 1994'.

c) A paragraph indicating the source materials which provided the background to the report, listing all those interviewed, with dates and place of interview, and listing all the documents, materials, tapes and reports in the order in which they were examined. In civil cases solicitors may ask for this list to be omitted so long as the decision has not been made to disclose to the other party all the documents supplied to the expert.

3. A brief description of the subject of the report should be made, e.g. 'Mr A.B. is an unmarried man 
of 45 years of age, of Indian background, who is employed as a fitter'.

4. Indication should be given that the subject has understood the purpose the interview and to whom the report will be sent.

5. The personal history of the subject should be provided with appropriate headings, in order that each section may easily be accessed and referenced by those using the report, e.g. 'family history', 'previous medical history', etc. Reference may be made to the source of information such as general practitioner records or specific hospital case notes in the text if the information does not derive from the interview with the person himself.

6. A previous history which is particularly relevant to the issue might be discussed under a separate heading, e.g. 'psychiatric history', relating to episodes of illness, treatment and outcome; serial admissions to psychiatric hospitals or referral to psychiatrists for assessment. A history of drinking behaviour, substance abuse, or of sexual problems may also merit a separate section. In criminal cases the history of delinquency is likely to be relevant and may not necessarily be consistent with a criminal record provided.

7. The background established above may conflict with information obtained from witnesses in statements provided or by interviews with relatives or others. These differences may be of minor significance and in appropriate cases, such as civil actions, may be reconciled before a final revised report is produced. The expert may draw attention at this stage to chronological or other anomalies remembering that this part of the report is concerned with the description of facts and not opinion.

8. The next section should report the account provided by the patient of his recollection of the matter with which the report is concerned (e.g. alleged criminal behaviour; accident; a medical treatment received; response to treatment and any previous assessment).

9. The report should continue with the findings arising from the psychiatric assessment of the patient, including positive and negative findings, describing the results of a comprehensive mental state assessment, and relevant observations of the presentation of the patient during the interview and the manner in which he gave his history and responded to questioning.
10. It can sometimes be helpful to the reader to include at this stage a discussion bringing together the salient points, explaining the relationship between them, and explaining in lucid terms complicated material. This section is often unnecessary but should be considered to assist lay readers in complex cases where the author wishes to draw attention to conflicting findings and their significance, to emphasise discrepancies or to discuss possible psychopathology before moving to the final opinion.

11. Having presented the facts and discussed the important principles in the report, the author should now give his opinion under a separate heading. The structure of this section, which can conveniently be laid out in numbered paragraphs, will of course depend upon the issues being addressed in the report. It is important not to confine the opinion to a few lines, but to range widely providing reasonable justification for conclusions and dealing with each important matter separately. For example in a claim for compensation following injury, the history, previous personality and behaviour of the subject might be discussed first. A description of the

Box 4. Layout of a medico-legal report

Topic of report

Introduction

When and where interviewed

Others interviewed

Papers, reports, documents examined

Brief description of subject

Patient's understanding of the interview

Personal history:

childhood, education, employment, marital and sexual history, drinking behaviour, substance abuse etc.

Family history

Previous medical history

Previous psychiatric history

Specific topics of relevance

Patient's account of matter under consideration

Examination

Discussion

Opinion

Name, qualifications and main appointment Date 
psychological injuries resulting from the accident might follow, with an opinion on the nature of the patient's suffering, the longer term disabilities and the degree of loss of function. An evaluation of the suffering and reduction in lifestyle compared with the pre-accident condition of the patient should be made.

The report should discuss the prognosis, likely response to treatment and, if it is possible to do so, the extent to which the accident is responsible for the present state. Any previous evidence of psychiatric illness may weigh against the case of the accident being totally, or even partially, responsible for the change in the patient's condition.

In criminal cases, a discussion of criminal responsibility with any indication of factors which might reduce or mitigate it should precede recommendations regarding disposal. Disposals should clearly indicate whether or not arrangements can be made for admission to hospital or for a form of treatment.

12. The report should conclude with the author's name, qualifications and principal appointment. In civil rather than in criminal cases, a brief curriculum vitae of the author may be requested; this can be sent on a separate sheet or included at the beginning or end of the report.

\section{Specific issues requiring a medico-legal report}

Requests for 'a psychiatric report' should not be accepted until the referring agent has made clear which issues should be addressed. The psychiatrist might otherwise reasonably conclude that the lawyer has embarked upon a 'fishing expedition'. The issues are usually relevant to a specific class of case and experts are, by definition, aware of this. Some cases are almost exclusively psychiatric questions, while others are primarily legal issues. When dealing with legal issues, the writer should be aware which among them are of specific concern so that he may address them using the appropriate legal wording.

The following are examples of legal issues which require an expert psychiatric opinion in the form of a report with a negative or positive conclusion.

Fitness to plead. Can the accused understand the nature of the charge against him and plead with understanding to it? Is he able to instruct his legal advisers? Could he follow and understand the evidence given in court? Would he be able to challenge a juror?

Insanity. At the time (of the act) was the accused labouring under such a defect of reason, from disease of the mind, as not to know the nature and quality of the act he was doing or, if he did know it, did he know that what he was doing was wrong? (McNaughton Rules 1843)

Diminished responsibility. At the time of the killing did he (the accused) suffer from such abnormality of mind (whether arising from a condition of arrested or retarded development of mind, or any inherent causes, or induced by disease or injury) as substantially impaired his mental responsibility for his acts or omissions in doing or being a party to the killing? (Section 2(1) Homicide Act 1957)

Infanticide. At the time of the death of her child was the balance of the woman's mind disturbed by reason of her not having fully recovered from the effect of giving birth to the child or by reason of the effect of lactation consequent upon the birth of the child? (Section 1(1) Infanticide Act 1938).

Opinions for mental health review tribunals. Just as it is important to be precise in completing the forms used in detaining a patient so that the specific requirements of the detaining section are met, it is equally necessary, when making a recommendation to a mental health review tribunal, to consider the conclusions that the tribunal will have in mind. For example, an application for discharge from detention under Section 3 Mental Health Act 1983 will be accepted if the tribunal is satisfied:

i) that the patient is not suffering from mental illness, psychopathic disorder, severe mental impairment, or from any of those forms of disorder of a nature or degree which make it appropriate for him to be detained in hospital for medical treatment; or

ii) that it is not necessary for the health or safety of the patient or for the protection of other persons that he should receive such treatment; or

iii) that (in relevant cases) he would be likely to act in a manner dangerous to other persons or to himself (Section 72(1)(b) Mental Health Act 1983).

Reference to other appropriate sections of the Act should be made for the precise wording under consideration when discharging other categories of patients.

Where reference to a statute requiring psychiatric evidence is necessary (as above) it helps the court or tribunal for the author to consider the 
precise wording used in his report. It should be remembered that these are legal classifications and definitions which have a meaning that has usually been defined in law. They are not necessarily directly equivalent to clinical diagnoses and classifications. Reference should be made to forensic and medico-legal texts for discussions of the meaning of terms such as 'abnormality of mind' (Homicide Act) or the McNaughton Rules.

\section{Additional information}

Those preparing medico-legal reports for specific purposes such as a defence of diminished responsibility or fitness to plead should possess an appropriate knowledge of the law. This should be evident in the way the opinion is provided. Lawyers rarely request references to published work in civil and criminal cases to substantiate an opinion, and are not usually impressed by excessively legalistic presentations. They are seeking a psychiatric, not a legal, opinion. The psychiatrist should always try and anticipate the requirements of lawyers and the court.

\section{Subsequent events}

When the report is required in connection with court proceedings the psychiatrist should always expect that he may be called to give evidence. When preparing the report he should therefore always remember that he may be faced with it in public and it may be subject to detailed scrutiny. In both criminal and civil cases the report will, however, frequently be accepted without the need for oral evidence.

The report may require revision after a conference with counsel or, in civil cases, other experts. Lawyers may suggest changes but cannot insist on them or give any impression that they are influencing the final opinion.

Reports between experts may be exchanged under the guidance of lawyers; in civil and criminal cases, it is increasingly common for doctors briefed by opposing sides to consult each other.

Finally, it is worth remembering that the report required by a defending solicitor may not be used at the time. It is the prerogative of the solicitor to decide whether or not it is of assistance to his client.
The report may, for instance, be helpful in indicating to the lawyer that he is going in the wrong direction. It may also have a long life in the records and be consulted again, even after a considerable time, in connection with a new appeal, future offending, parole or other circumstances.

\section{Further guidance}

More detailed advice on writing a report, but with particular reference to psychiatric reports, mental health review tribunals, hospital managers, the Home Office for restricted patients and the transfer of patients to special hospitals and prisons, and for Mental Health Act Commission second opinions, is available from Faulk (1994) and Bluglass (1995), where further advice on compensation reports is also available with specimen reports for both criminal and civil proceedings. Bowden (1990) and Gunn \& Taylor (1993) also provide valuable advice on reporting to the criminal court. Briscoe (1990) discusses court reports in civil cases involving children, and Storey (1990) and Cornes \& Aitken (1990) discuss reports for compensation following injury. Blacket al (1991) provide a helpful chapter on writing reports for cases involving children. Powers \& Harris (1994) give comprehensive guidance on reports on medical negligence in a detailed textbook.

\section{References}

Black, D., Wolkind, S. \& Harris Hendricks, J. (1991) Child Psychiatry and the Law (2nd edn). London: Gaskell.

Bluglass, R. (1995) Writing reports and giving evidence. In Seminars in Practical Forensic Psychiatry (eds D. Chiswick \& R. Cope). London: Gaskell.

Bowden, P. (1990) The written report and sentences. In Principles and Practice of Forensic Psychiatry (eds R. Bluglass \& P. Bowden). Edinburgh \& London: Churchill Livingstone.

Briscoe, O. (1990) Court reports: civil cases involving children. In Principles and Practice of Forensic Psychiatry (eds R. Bluglass \& P. Bowden). Edinburgh \& London: Churchill Livingstone.

Cornes, P. \& Aitken, R. C. (1990) Medical reports on persons claiming compensation for personal injury. Journal of the Royal Society of Medicine, 85, 329-333.

Faulk, M. (1994)Forensic Psychiatry (2nd edn). Oxford: Blackwell Scientific Publications.

Gunn, J. \& Taylor, P. (1993) Forensic Psychiatry: Clinical, Ethical and Legal Issues. Oxford: Butterworth-Heinemann.

May, R. (1995) Criminal Evidence (3rd edn). London: Sweet \& Maxwell (in press)

Powers, M. \& Harris, N. (1994) Medical Negligence (2nd edn). London: Butterworths. 
Storey, P. (1990) Reports for compensation after injury. In: Principles and Practice of Forensic Psychiatry (eds R. Bluglass \& P. Bowden). Edinburgh \& London: Churchill Livingstone.

\section{Multiple choice questions}

1 A report to a criminal court:

a should state whether or not the accused is fit to plead.

b may include an opinion on the guilt of the accused.

c is confidential to the lawyer requesting it.

d should refer to all the sources of information.

2 The medico-legal report:

a should enhance the case of the party requesting it.

b will always be revealed to both sides.

c should be as brief as possible.

d should anticipate the court's conclusions.
3 In civil cases:

a the report is the property of the agent requesting it.

b all the documents studied should be revealed in the report.

c the report should identify a previous history of relevant illness.

d the report should recommend the damages to be awarded.

\begin{tabular}{|c|c|c|}
\hline \multicolumn{3}{|c|}{ MCQ answers } \\
\hline 1 & 2 & 3 \\
\hline a $T$ & a $\mathbf{F}$ & a $\mathbf{T}$ \\
\hline b $\mathbf{F}$ & b $\mathbf{F}$ & b F \\
\hline c $\mathbf{F}$ & c $\mathbf{F}$ & c $\mathbf{T}$ \\
\hline d $\mathbf{T}$ & d $\mathbf{T}$ & d F \\
\hline
\end{tabular}

\section{Forthcoming CPD workshops}

Diagnosis, gender and culture

Friday 9 June 1995

9.30 a.m. -4.45 p.m.

Royal College of Psychiatrists
Epilepsy

Wednesday 1 November 1995

10.00 a.m. -5.00 p.m.

Royal College of Psychiatrists

For further information please contact Annabel Thomas, CPD department at the College (tel. 01712352351 Ext. 145). 